\title{
Assessment of Human Stability in Sewer Systems during Dry Weather Conditions
}

\author{
Beniamino Russo ${ }^{1,2, *(\mathbb{D}}$, Luca Locatelli ${ }^{1}$ (D), Daniel Yubero ${ }^{1}$, Oscar Ruiz $^{2}$ (D) and Alejandro Acero Oliete ${ }^{2}$ \\ 1 AQUATEC (SUEZ Group), Unit of Climate Change and Resilience, 08038 Barcelona, Spain; \\ luca.locatelli@aquatec.es (L.L.); dyuberop@aquatec.es (D.Y.) \\ 2 Group of Hydraulics and Environmental Engineering (GIHA), Technical College of La Almunia (EUPLA), \\ University of Zaragoza, 50100 Zaragoza, Spain; oruiz@unizar.es (O.R.); acero@unizar.es (A.A.O.) \\ * Correspondence: brusso@unizar.es or brusso@aquatec.es
}

Citation: Russo, B.; Locatelli, L.; Yubero, D.; Ruiz, O.; Oliete, A.A. Assessment of Human Stability in Sewer Systems during Dry Weather Conditions. Water 2021, 13, 2954. https://doi.org/10.3390/ w13212954

Academic Editor: Christos Makropoulos

Received: 26 September 2021

Accepted: 16 October 2021

Published: 20 October 2021

Publisher's Note: MDPI stays neutral with regard to jurisdictional claims in published maps and institutional affiliations.

Copyright: (c) 2021 by the authors. Licensee MDPI, Basel, Switzerland. This article is an open access article distributed under the terms and conditions of the Creative Commons Attribution (CC BY) license (https:// creativecommons.org/licenses/by/ $4.0 /)$.

\begin{abstract}
Inspection and maintenance tasks are essential to guarantee the correct operation of sewer drainage networks. In combined sewers, these tasks are generally carried out during dry periods when only wastewater flow circulates in the system. When the sewer is big enough to allow the access of people, this inspection is done in person with consequent potential exposure to several hazards such as the presence of toxic gases, the possibility to fall or the loss of stability due to the presence of a continuous wastewater flow. In this context, this paper presents a methodology to assess hazard conditions related to human stability in sewer systems during dry weather periods. Hazard assessment has been performed by applying several hazard criteria to the results of a 1D sewer model simulations regarding a real network in Spain. Results show that the influence of the selection of hazard criteria is relevant, although only a small part of the whole system can be classified as high hazard. Regardless, the proposed method is highly effective to detect these kinds of pipes and we consider them as critical point to improve health and safety procedures during maintenance and inspection tasks.
\end{abstract}

Keywords: health and safety; hazard criteria; sewer system inspection; wastewater modelling

\section{Introduction}

The inspection and maintenance of sewers pipes are necessary tasks to achieve the correct operation of sewer drainage networks. Inspections of sewers are performed as part of the network maintenance or because of an emergency. In the case of a combined network, inspections are carried out in dry time and maintenance is performed when an emergency appears. Although, in general, the lifespan of collectors is very long, hundreds of years in some cases [1] and multiple causes require inspection [2,3]. The sewers gather discharges from different origins that can have a negative impact on the pipes, mainly if the discharges are industrial [2]. Runoff can carry a multitude of elements that can hinder the water transport capacity of the network. External loads can break the walls of the pipeline, and so on.

The inspection of the collectors is mainly done by closed circuit television video (CCTV) [4], but when the sewer is big enough to allow the access of people, this inspection is done in person [2]. Inspectors can directly observe pipeline problems, perform repairs, define maintenance works, etc. The workers who go into the collector are exposed to several hazards associated with the environment in which the work is performed. The most common hazards are those related to gases (methane and inflammable gases, hydrogen sulphide, carbon monoxide, and other toxic gases), although falling and loss of stability are other important causes of injuries [1]. The sewers are considered confined spaces and working in them has to fulfil the confined spaces safety procedures. The presence of water in a large collector is unavoidable. Furthermore, it is not possible to isolate main collectors that serve important parts of the city. For all these reasons, inspection and maintenance 
tasks must be carried out despite the water flow. Even if the safety measures required for this type of work are taken, the water flow can endanger workers, dragging or hitting them.

Pedestrian stability in water streams is usually assessed based on the hydrodynamic characteristic of the flow (generally water depth and velocity). Several experimental and numerical studies about human stability in floodplains were conducted in the last decades [5-7]. More recently, specific hazard criteria related to pedestrian stability in flooded streets were achieved by experimental campaigns performed at the hydraulic laboratory of the Technical University of Catalonia [8,9].

Studies about people stability in sewer networks are not available in literature, notwithstanding several injuries occur every year worldwide.

The following publicly available statistics (Table 1) show some mortal accidents occur in sewers every year but is difficult to determine the real cause of the fatalities within the total number of work accident statistics. The most common accidents associated with the dragging of workers through the water, "baths" of varying severity, are not included in these accident statistics.

Table 1. Deaths in sewers, last full year with available data.

\begin{tabular}{cccc}
\hline Year & Spain $^{\mathbf{1}}$ & USA $^{2}$ & UE $^{\mathbf{3}}$ \\
\hline 2019 & 2 & 8 & NA \\
2018 & NA & NA & 0 \\
\hline
\end{tabular}

${ }^{1}$ Deaths in sewers; work accident statistics 2019; Ministry of Labour and Social Economy, Kingdom of Spain.

2 Accident search results using keyword "sewer"; Occupational Safety and Health Administration; Department of Labor, USA.

${ }^{3}$ Accidents at work by sex, age, severity, NACE Rev. activity and working environment; Eurostat. Water supply; sewerage, waste management and remediation activities. Accidents on/over water, excluding construction sites. In 2019, the only available data were from Spain and Cyprus.

Outside of the EU and the USA, the problem could be more critical due to existing health and safety standards. For example, in India, recent official statistics show that 2019 saw the highest number of deaths while engaged in such work in the past five years. As per official statistics, a total of 376 laborers died while performing the task since 2015, while 2019 alone accounted for 110 of these deaths [9].

Regarding the size of the sewer pipes that allows the inspection in person, regulatory bodies and the companies managing drainage networks generally use their own criteria that are quite similar. The following four examples are provided:

- The "Technical guide on sanitation and urban drainage networks" of the CEDEX (Centro de Estudios y Experimentación de Obras Públicas or Centre for Studies and Experimentation of Public Works in English), depending on the Spanish Ministry of Development establishes as a definition of visitable collectors those with a minimum height of $160 \mathrm{~cm}$ and minimum width of $60 \mathrm{~cm}$ [10].

- The Barcelona City Council differentiates three levels of visitable drainage networks: visitable (height or diameter $\geq 150 \mathrm{~cm}$ and width $\geq 60 \mathrm{~cm}$ ), semivisitable (height or diameter $\geq 100 \mathrm{~cm}$ and width $\geq 50 \mathrm{~cm}$ ) and nonvisitable (height or diameter $<100 \mathrm{~cm}$ or width $<50 \mathrm{~cm}$ ) [11].

- In the Madrid region, norms about sewer networks elaborated by Canal de Isabel II consider as nonvisitable pipes all the sewers with a height $<180 \mathrm{~cm}$. Pipes with a height $\geq 180 \mathrm{~cm}$ could be considered visitable only if they have a separate footpath from the wastewater flow circulating in a gutter or in case flow conditions support a flow depth $\leq 9 \mathrm{~cm}$ and a flow velocity $\leq 1.5 \mathrm{~m} / \mathrm{s}$ [12]. This reference is the only one establishing geometric and flow criteria to define visitable sewer pipes.

- The company Lyonnaise des Eaux (France) uses these levels: visitable (height or diameter $\geq 160 \mathrm{~cm}$ ), semivisitable (height between 120 and $160 \mathrm{~cm}$ ) and nonvisitable (height $<120 \mathrm{~cm}$ ) [13]. 
- ATCO (Asociación de Fabricantes de Tubos de Concreto, in English Association of Concrete Pipe Manufacturers, Mexico) sets the visitable threshold of a circular collector at a diameter greater than $800 \mathrm{~mm}$ [13].

- The manual of urban drainage of the Ministry of Public Works of Chile considers sewers visitable if their diameter is at least $160 \mathrm{~cm}$ [14].

In this context, this paper presents results regarding human stability in combined sewer systems during dry weather conditions for a real case in Badalona (Spain), applying specific hazard criteria in visitable pipes of the existing sewer network of the city and using the flow results provided by a calibrated $1 \mathrm{D}$ sewer model $[15,16]$. The results of the study can be extrapolated to any other sewer networks and help to improve health and safety procedures established by municipalities and utility managers, related to inspection and maintenance tasks of sewer systems assets.

\section{Materials and Methods}

\subsection{Description of the Case Study}

Badalona is a city in eastern Catalonia (Spain) and is part of the Barcelona metropolitan area (Figure 1a). It is situated on the left bank of the Besòs River and on the Mediterranean Sea, backed by the Serra de la Marina mountain range. With 220,000 inhabitants, Badalona is the fourth most-populated municipality in Catalonia. The morphology of Badalona catchments is characterized by high gradients (with an average of $4 \%$ ) in the upper part of the city and very flat areas in the downtown. Moreover, a great part of the land of the municipality was strongly urbanized during the last centuries. All these aspects, together with the Mediterranean rainfalls characterized by high intensity and short duration, leave the city in a flood-prone situation [17].

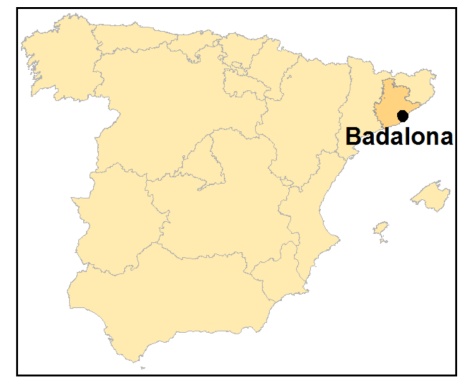

(a)

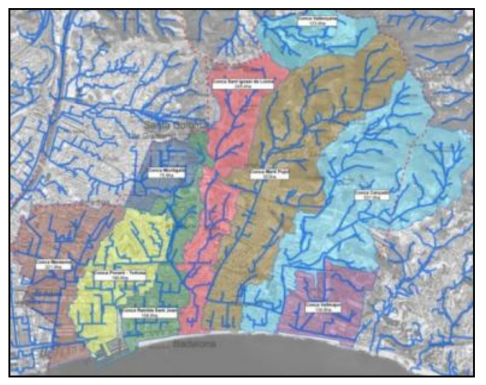

(b)

Figure 1. (a) Location of the city of Badalona; (b) Main water courses and catchments.

On the other hand, Badalona presents several kilometres of beaches with a significant impact on the tourism of the city. During rain events, part of the stormwater not entering into WWTPs generates combined sewer overflows (CSOs) with significant social and economic damage related to the inability to bath in the waters [16]. Specifically, Badalona has more than 15 points with potential CSOs (Figure 2).

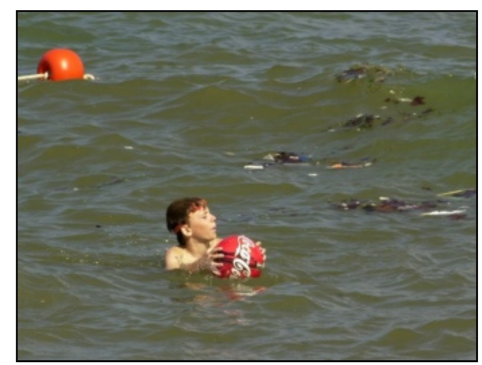

(a)

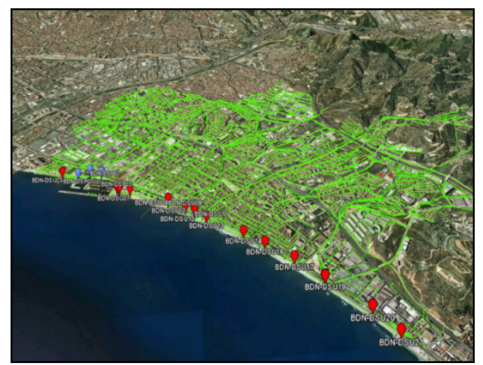

(b)

Figure 2. (a) Floating solids in Badalona bathing waters after a CSO; (b) Locations of sewer network CSO points. 
In this context, both hydraulic and environmental issues highlight the relevance of correct and adequate design, maintenance (including cleaning to remove sewer sediment), and operation of the drainage network $[16,17]$.

Badalona's drainage network is a combined sewer system with $322 \mathrm{~km}$ of conduits, with $41 \mathrm{~km}$ allowing man-entry (considered as visitable). The main part of the sewer system is managed by the municipality of Badalona, while the rest (supramunicipal main pipes and interceptors) is managed by Barcelona metropolitan authority because it serves more than one city.

The inspection and maintenance of Badalona's sewer pipes are necessary tasks to achieve the correct operation of sewer drainage networks. Inspections of the sewers are performed as part of network maintenance or because of an emergency with a frequency of once per year. Inspections of visitable collectors are performed by specialized workers that enter the sewer systems through manholes and take photos about the state of the pipes material and the sediment accumulation. In case of significant problems, the pipes are cleaned by specialized machines and further inspections by CCTV are scheduled. Cleaning tasks are generally performed with a frequency of once or twice per year, only for the parts of the systems with observed sediment above $20 \%$ of the sewer height.

\subsection{Hazard Criteria Adopted for Human Stability Assessment}

As mentioned in the previous sections, studies about people stability in floodplains are quite common in literature, while recent experimental campaigns have been developed to achieve hazard criteria related to pedestrian stability in flooded streets produced by heavy rainfall events. Studies about human stability designed to improve health and safety protocols regarding sewer inspections during dry periods are not available in the literature, notwithstanding several injuries occur every year worldwide.

The aim of this study is the analysis of the potential instability of people inside combined sewer pipes during dry weather conditions, when only wastewater flows in the conduits. Although no specific study about hazard criteria has been conducted in sewer systems, and several differences can be appreciated (i.e., sewers are confined spaces where access is limited to trained workers and the flow transports debris and organic matter), in this study the authors decided to use similar hazard criteria to the ones adopted by Russo et al. [7] and Martínez et al. [8] due to the following reasons:

- In their experimental campaigns, a model representing an urban street in real scale was designed and built, using factory and concrete materials (Figure 3). The roughness of the platform of the physic model can be assumed to be similar to the roughness of concrete pipes in sewer systems.

- Tests were conducted using different types of shoes including waterproof boots normally used during sewer inspection. It should guarantee a similar friction between the bottom of the platform and the subjects. During the tests, the conditions experienced during inspections were maintained, where friction is experimented between the bottom of the pipe and the workers.

- Tests were conducted considering different visibility conditions. Particularly, glasses were used to decrease visibility during some tests in order to take into account the possibility that pedestrians do not have high visibility conditions during flooding events (i.e., floods event occurring at night, people with wetted and fogged glasses, etc.). This aspect could be relevant due to the absence of natural lighting in sewer networks.

- Last but not least, the flow parameters achieved during the tests carried out by Russo et al. [8] and Martínez et al. [9] were characterized by low flow depths and high flow velocity. These conditions are typical in urban flooded areas where the surface presents a low roughness and they fit quite well with respect to the flow conditions in sewers where a low flow rate is normally observed in the gutter or where circular and ovoid pipes flow with high velocity to avoid sedimentation problems. 


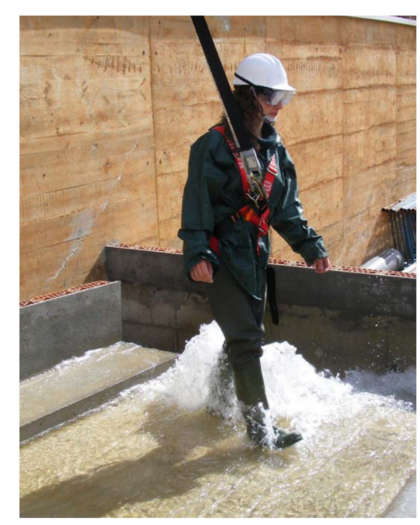

Figure 3. Tests on human stability in flooded streets carried out during the experimental campaign at the hydraulic laboratory of the Technical University of Catalonia [7].

Therefore, the criteria adopted for the hazard assessment concerning human stability in sewer networks were similar to the ones established by Russo et al. [7] and Martínez et al. [8] for flooded streets during pluvial flooding events. Specifically, in a flow depth $(D)$ - flow velocity $(v)$ chart, the proposed threshold for high hazard conditions was the zone beyond the product $(v \cdot D)=0.22 \mathrm{~m}^{2} \cdot \mathrm{s}^{-1}$. Other authors proposed other similar products, such as $(v \cdot D)=0.4 \mathrm{~m}^{2} \cdot \mathrm{s}^{-1}$ and $(v \cdot D)=0.6 \mathrm{~m}^{2} \cdot \mathrm{s}^{-1}$ proposed by Shand et al. [7] as stability criteria to be adopted for children and adults moving in flooded watercourses, respectively. Furthermore, other previous studies proposed as threshold a product $(v \cdot D)$ around $0.5 \mathrm{~m}^{2} \cdot \mathrm{s}^{-1}[5,18,19]$. On the other hand, a maximum flow depth $(D)$ should be established in order to ensure the manoeuvrability and the safety of the workers during sewer inspections.

As a result, if this maximum flow depth is established, a high-hazard zone can be generally defined as shown in Figure 4.

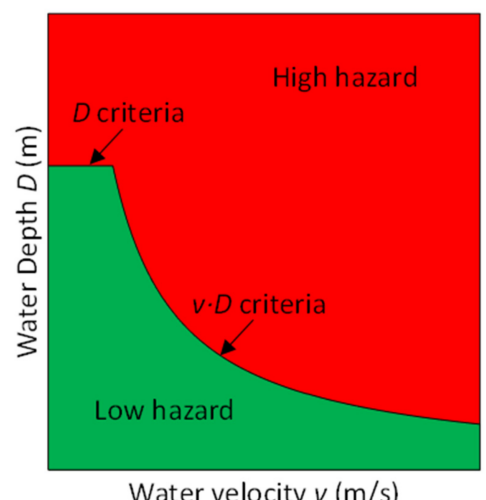

Figure 4. Hazard criteria adopted for the assessment of human stability in sewer pipes during dry weather conditions.

\subsection{Wastewater Flow Model}

The wastewater flow model of Badalona was described in detail by Martínez et al. [16] and Locatelli et al. [16,19]. The drainage network of Badalona is almost entirely a combined sewer system and the model can include both stormwater and wastewater flows.

The objective of the 1D wastewater flow model of Badalona is to simulate water flow depth and velocities in the sewer network of Badalona during dry weather periods.

The original urban drainage model was first developed in MIKE URBAN for the drainage management plan (DMP) of Badalona in 2012. Then, the model was imported into InfoWorks ICM 8.5, modified and updated to be used for different purposes in two different projects: the integrated urban drainage master plan (PDIS Besòs in Catalan) of the Besòs River and two European projects within the framework of the H2020 and LIFE 
programmes (respectively, BINGO and EFFIDRAIN projects). Two different versions of the model were created: a 1D/2D model to simulate two-dimensional urban flooding and a 1D model to simulate combined sewer overflows.

The wastewater flow model of Badalona used in this paper is the 1D version. It includes approximately $368 \mathrm{~km}$ of pipes, 11,338 manholes, 62 weirs, 4 sluice gates, one detention tank of approximately $30,000 \mathrm{~m}^{3}$ and 11,954 subcatchments. The area of Badalona was divided into 11,954 hydrological subcatchments of different areas (in the range of 0.01-1 ha in the urban areas and 1-100 ha in the upstream rural areas) in order to simulate rainfall-runoff processes and domestic and industrial sewage water fluxes. In dry weather scenarios, subcatchments are used only as a source of wastewater. For each subcatchment a wastewater flow was assigned based on spatially distributed data of registered potable water sold to consumers, provided by the water utility. By dividing the total wastewater volume observed at the treatment plant by the population of Badalona, a value of $207 \mathrm{~L} /$ day/person was obtained and applied in the model. This value was considered reasonable after analysing the different flow rates of the flows reaching the Bèsos wastewater treatment plant (WWTP) during dry weather conditions. As a result, industrial, domestic, commercial, and other kinds of wastewater flows can be considered to be included. The hydraulic processes in the network pipes were simulated using the full 1D Saint-Venant equations.

The model was calibrated and validated with the aim of reproducing wet weather flow hydrographs and peaks. A calibration trial-and-error approach was applied with the objective function of minimizing the sum of all the root mean square errors (RMSEs) calculated for each observation point. Rainfall data and water level measurements in the sewer pipes during four different rain events were used. The calibrated model parameters were the Horton infiltration rates and the Manning coefficients of both subcatchments and pipes.

\subsection{Model Scenarios}

Based on the wastewater daily pattern obtained from water flow measurements at the wastewater treatment plant (Figure 5), three different steady-state simulations were performed corresponding to the following scenarios:

(a) Maximum flow-This scenario corresponds to the daily peak flow that according to the daily pattern shown in Figure 5 is 1.40 times the daily average flow.

(b) Average flow-This scenario corresponds to the mean daily flow.

(c) Minimum flow-This scenario corresponds to the daily minimum flow that according to the daily pattern shown in Figure 5 is 0.56 times the daily average flow.

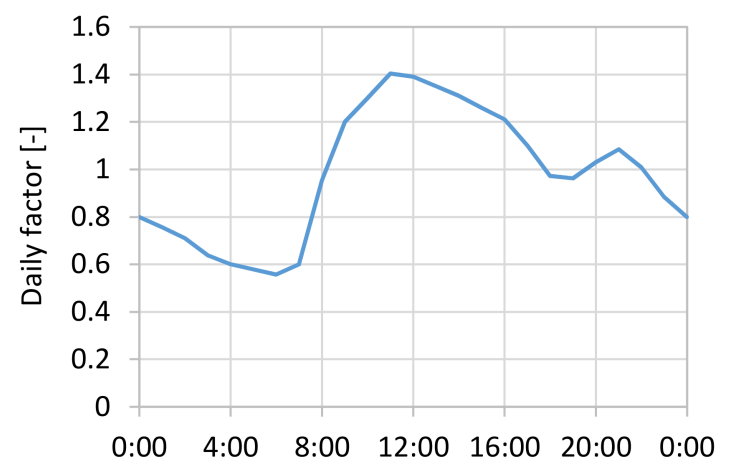

Figure 5. Wastewater daily factor.

For each of the three above mentioned scenarios, different hazard criteria were applied to discuss the effects of the chosen criteria on the final hazard results:

- Four $v \cdot D$ product criteria $\left(0.22,0.4,0.5\right.$, and $\left.0.6 \mathrm{~m}^{2} / \mathrm{s}\right)$

- Two water depth $D$ criteria (0.5 and $1 \mathrm{~m})$. 


\section{Results}

\section{Hazard Assessment}

Figure 6 shows an example of the simulated hazard maps obtained for the sewer pipes that are classified as accessible and for the maximum flow scenario. The figures represent the high- and low-hazard pipes for different $v \cdot D$ products $(0.22,0.4,0.5$, and $\left.0.6 \mathrm{~m}^{2} / \mathrm{s}\right)$ and for different flow depths $(0.5$ and $1 \mathrm{~m})$. The results show that most of the accessible/visitable conduits present low hazard (the green pipes in the figure). High hazard is mainly observed in the pipes that run parallel and close to the sea in the centresouth of Badalona (sewer interceptor of the combined system). This is a large sewer pipe of 1.6-2.0 $\mathrm{m}$ in diameter that collects all the sewer flow and carries it southward by gravity, where there is an elevation station that elevates the water by a few meters into another pipe that by gravity, flows towards the wastewater treatment plant.

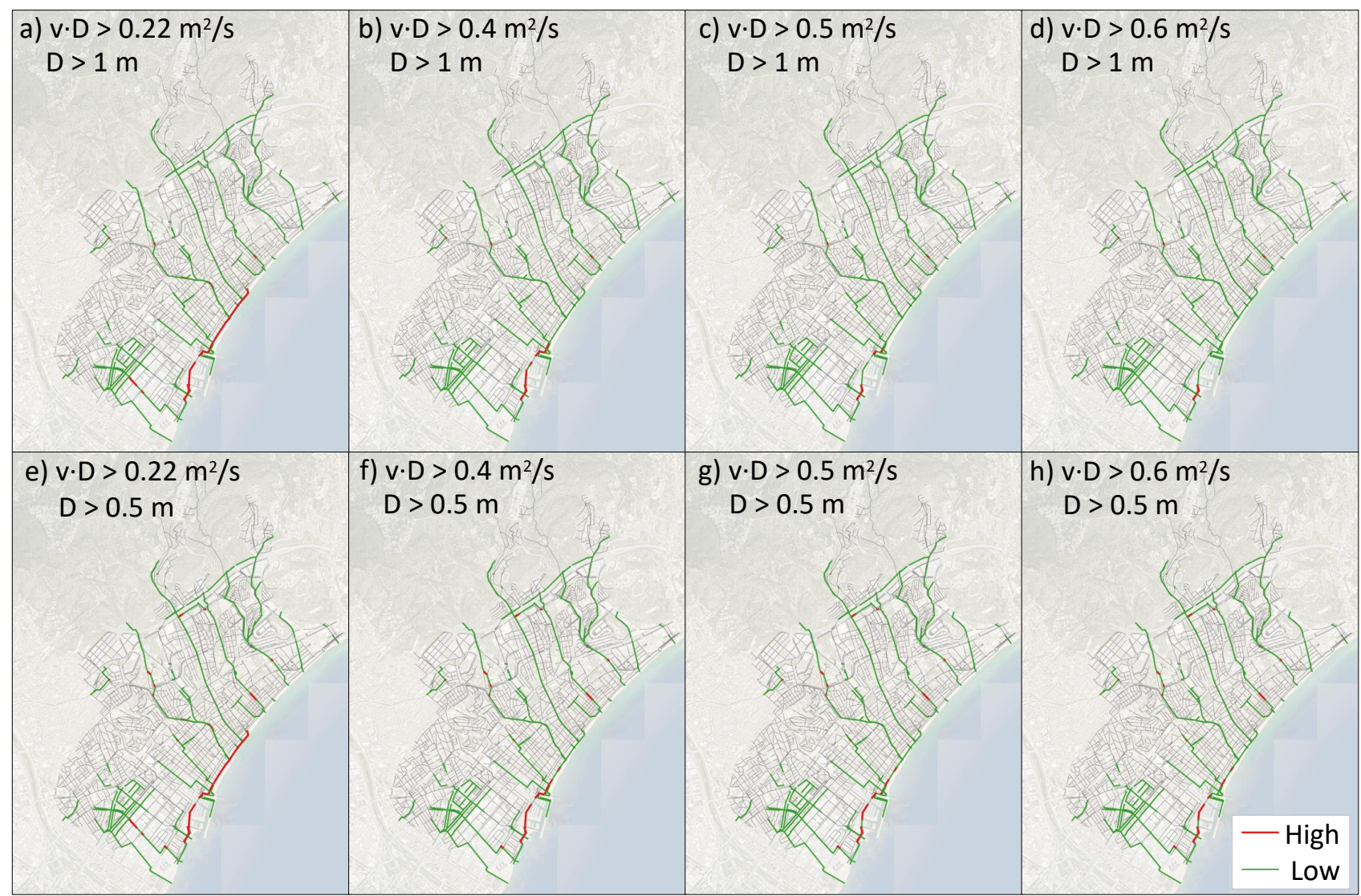

Figure 6. Hazard map of visitable sewer conduits in maximum flow scenario. Green lines = low-hazard, red lines = highhazard and grey lines = nonvisitable conduits.

High hazard in this case can be produced either by high water depth or by a combination of water depth and velocity. When looking in detail at specific pipes, there may be situations of very low velocities with high water depth in specific case like counter slope pipes or sewer syphons. In other cases, high-hazard conditions are produced by high water velocities and low depth that can occur at short high-slope pipes or pipes close to outlets.

Tables 2 and 3 show the pipe length and percentage of pipes with high hazard associated to each different scenario and for the different hazard criteria used. The results show that the longitude of visitable conduits with high hazard vary significantly depending on the $v \cdot D$ product and the two depth criteria proposed. It is to be noted that the total longitude of visitable conduits is approximately $41.6 \mathrm{~km}$. Therefore, the great majority of visitable conduits present low hazard (this can also be seen in the previous hazard maps). 
Table 2. Results of hazard assessment regarding human stability in Badalona sewer systems during dry weather conditions. Kilometres of visitable conduits with high hazard.

\begin{tabular}{cccccc}
\hline & & \multicolumn{4}{c}{ Kilometres of Visitable Conduits with High Hazard } \\
\cline { 2 - 5 } & & \multicolumn{4}{c}{$\mathbf{( \mathbf { m } ^ { \mathbf { 2 } } / \mathbf { s } )}$} \\
\hline \multirow{2}{*}{ Scenario } & Depth Criteria & $\mathbf{0 . 2 2}$ & $\mathbf{0 . 4}$ & $\mathbf{0 . 5}$ & $\mathbf{0 . 6}$ \\
\hline \multirow{2}{*}{ Max } & $\mathrm{D}>1 \mathrm{~m}$ & 2778 & 961 & 422 & 312 \\
\cline { 2 - 5 } & $\mathrm{D}>0.5 \mathrm{~m}$ & 3099 & 1572 & 1247 & 1138 \\
\hline \multirow{2}{*}{ Mean } & $\mathrm{D}>1 \mathrm{~m}$ & 2319 & 327 & 312 & 312 \\
\cline { 2 - 5 } & $\mathrm{D}>0.5 \mathrm{~m}$ & 2597 & 798 & 783 & 783 \\
\hline \multirow{2}{*}{ Min } & $\mathrm{D}>1 \mathrm{~m}$ & 619 & 312 & 312 & 312 \\
\cline { 2 - 5 } & $\mathrm{D}>0.5 \mathrm{~m}$ & 883 & 613 & 613 & 613 \\
\hline
\end{tabular}

Table 3. Results of hazard assessment regarding human stability in Badalona sewer systems during dry weather conditions. Percentage of visitable conduits with high hazard with respect to the total visitable ones.

Percentage of Visitable Conduits with High Hazard with Respect to the Total Visitable Ones

\begin{tabular}{cccccc}
\cline { 2 - 5 } Scenario & & \multicolumn{4}{c}{$\boldsymbol{v} \cdot \mathbf{D}\left(\mathbf{m}^{\mathbf{2}} / \mathbf{s}\right)$} \\
\hline \multirow{2}{*}{ Max } & Depth Criteria & $\mathbf{0 . 2 2}$ & $\mathbf{0 . 4}$ & $\mathbf{0 . 5}$ & $\mathbf{0 . 6}$ \\
\cline { 2 - 6 } & $\mathrm{D}>1 \mathrm{~m}$ & $6.7 \%$ & $2.3 \%$ & $1.0 \%$ & $0.8 \%$ \\
\hline \multirow{2}{*}{ Mean } & $\mathrm{D}>0.5 \mathrm{~m}$ & $7.5 \%$ & $3.8 \%$ & $3.0 \%$ & $2.7 \%$ \\
\cline { 2 - 6 } & $\mathrm{D}>1 \mathrm{~m}$ & $5.6 \%$ & $0.8 \%$ & $0.8 \%$ & $0.8 \%$ \\
\hline \multirow{2}{*}{ Min } & $\mathrm{D}>0.5 \mathrm{~m}$ & $6.2 \%$ & $1.9 \%$ & $1.9 \%$ & $1.9 \%$ \\
\cline { 2 - 6 } & $\mathrm{D}>1 \mathrm{~m}$ & $1.5 \%$ & $0.8 \%$ & $0.8 \%$ & $0.8 \%$ \\
\hline
\end{tabular}

Figure 7 shows the hazard assessment for all the simulated visitable conduits of the urban drainage model in the scenario with maximum flow. Each of the empty black circles represents the simulated velocity and flow depth of a conduit. This graph helps visualize how the choice of both hazard criteria $v \cdot D$ and $D$ affect the resulting hazard level (low or high). The pipes that show very low velocities with high water depth are generally caused by counter slope pipes or sewer siphons. In addition, high water velocities and low depths generally occur at high-slope pipes or close to outlets. 


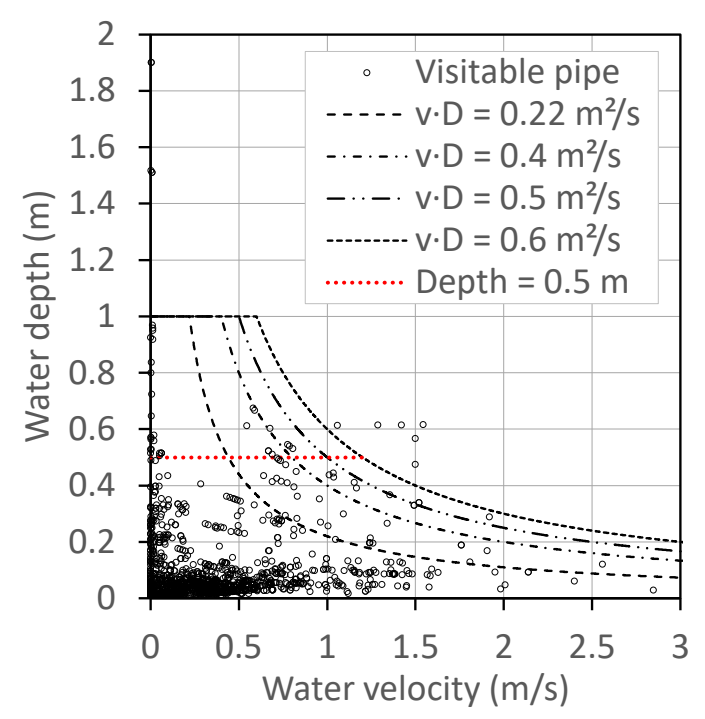

Figure 7. Hazard assessment for all the simulated visitable conduits of the urban drainage model in the scenario with maximum flow. Different $v \cdot D$ products and depth criteria are also shown.

\section{Conclusions}

This paper presents a methodology to assess hazard conditions related to human stability in sewer systems during dry weather periods. The wastewater flow depths and velocity have been estimated through a calibrated 1D sewer model for three wastewater flow scenarios (maximum, medium, and minimum scenarios). The maximum flow scenario corresponding to the daily peak flow (1.40 times the daily average flow) was the chosen one, in this case, for representing the hazard maps being the worst case.

Hazard assessment was performed by applying several hazard criteria commonly used to express human stability on flooded water streams characterized by high flow velocities. Specifically, several products $v \cdot D$ and two water depths $D$ were considered for the set of data results provided by the models from the three simulated scenarios. The analysis shows that the influence of the choice of hazard criteria to determine the length of high-hazard pipes is quite high for the maximum wastewater flow scenario.

Notwithstanding, it should be noted that a major part of the accessible sewer pipes can be considered as safe for all three flow scenarios, independently of the selected hazard criteria. High hazard conditions are mostly related to sewer interceptors and other counter slope pipes or sewer siphons. Furthermore, high water velocities and low depths generally occur at high-slope pipes or close to outlets.

The methodology proposed, which could easily be replicated in any other sewer networks, has a strong relevance to detect critical points for the safety of sewer workers during inspections and maintenance tasks. From a practical point of view, this kind of study could be used as a useful tool to improve the health and safety plans and programs of the entities and utilities that manage and exploit sewer networks.

The study presents some limitations due to the application of flood hazard criteria (devised for surface waters) to confined spaces such as sewer networks characterized by the presence of flow transporting debris and organic matter. In order to fill this gap, future experimental works should be carried out to develop specific hazard criteria for human stability hazard in sewer conduits.

Author Contributions: Conceptualization: B.R. and L.L.; methodology: B.R. and L.L.; software: L.L.; D.Y.; validation: B.R. and L.L.; formal analysis: B.R. and O.R.; investigation: B.R., L.L. and O.R.; resources: B.R., D.Y., A.A.O. and O.R.; data curation: A.A.O. and O.R.; writing-original draft preparation B.R., L.L. and O.R.; writing-review and editing: B.R., L.L. and A.A.O.; visualization: D.Y. and L.L.; supervision: B.R.; project administration: B.R. and A.A.O.; funding acquisition: A.A.O., B.R., O.R. All authors have read and agreed to the published version of the manuscript. 
Funding: This research received no external funding.

Institutional Review Board Statement: Not applicable.

Informed Consent Statement: Not applicable.

Acknowledgments: The results presented in this article come, in part, from the research activity of the Group of Hydraulic and Environmental Engineering (GIHA) of the EUPLA (group recognized by the Government of Aragon, Spain). The authors also appreciate the collaboration of the Badalona City Council in providing essential information for the development of the study.

Conflicts of Interest: The authors declare no conflict of interest.

\section{References}

1. Haurum, J.B.; Bahnsen, C.H.; Pedersen, M.; Moeslund, T.B. Water level estimation in sewer pipes using deep convolutional neural networks. Water 2020, 12, 3412. [CrossRef]

2. Tscheikner-Gratl, F.; Caradot, N.; Cherqui, F.; Leitão, J.P.; Ahmadi, M.; Langeveld, J.G.; Le Gat, Y.; Scholten, L.; Roghani, B.; Rodríguez, J.P.; et al. Sewer asset management-state of the art and research needs. Urban Water J. 2019, 16, 662-675. [CrossRef]

3. Lee, J.; Park, C.; Baek, S.; Han, S.; Yun, S. Risk-based prioritization of sewer pipe inspection from infrastructure asset management perspective. Sustainability 2021, 13, 7213.

4. Hansen, B.D.; Rasmussen, S.H.; Uggerby, M.; Moeslund, T.B.; Jensen, D.G. Comprehensive feature analysis for sewer deterioration modeling. Water 2021, 13, 819. [CrossRef]

5. Abt, S.R.; Wittler, R.J.; Taylor, A.; Love, D.J. Human stability in a high flood hazard. Water Resour. Bull. 1989, 25, 881-890. [CrossRef]

6. Shand, T.; Cox, R.J.; Smith, J.; Blacka, M. Appropriate criteria for the safety and stability of people in stormwater design. In Proceedings of the National Conference of the Stormwater Industry Association, Sydney, Australia, 8-12 November 2010; pp. $1-12$.

7. Russo, B.; Gómez, M.; Macchione, F. Pedestrian hazard criteria for flooded urban areas. Nat. Hazards 2013, 69, 251-265. [CrossRef]

8. Martínez-Gomariz, E.; Gómez, M.; Russo, B. Experimental study of the stability of pedestrians exposed to urban pluvial flooding. Nat. Hazards 2016, 82, 1259-1278. [CrossRef]

9. Deccan Herald. 2019 Records Highest Deaths while Cleaning Sewer in Last 5 Years. 2019. Available online: https:// www.deccanherald.com/national/2019-records-highest-deaths-while-cleaning-sewer-in-last-5-years-807401.html (accessed on 15 October 2021).

10. Centro de Estudios y Experimentación de Obras Públicas (CEDEX). Guía Técnica Sobre Redes de Saneamiento y Drenaje Urbano; Ministerio de Fomento, Ed.; Gobierno de España: Madrid, Spain, 2009; ISBN 978-84-7790-491-5.

11. Clavegueram de Barcelona S.A. (CLABSA). Pla Especial de Clavegueram de Barcelona (PECLAB '97) [(Barcelona Drainage Master Plan, 1997)]; CLABSA: Barcelona, Spain, 1997.

12. Canal de Isabel II. Normas Para Redes de Saneamiento. 2020. Available online: https://www.canaldeisabelsegunda es/documents/20143/79037/2016_Normas_Redes_Saneamiento.pdf/e1461e6b-3e64-8356-2b8f-05ee9845c4d8 (accessed on 15 October 2021).

13. Escuela del Agua (SUEZ Spain). Limpieza Avanzada de la Red de Drenaje, 2nd ed.; MOOC (Massive Open Online Course); 2021; Available online: https:/ / miriadax.net/web/limpieza-avanzada-de-la-red-de-drenaje-2-edicion-/inicio (accessed on 15 October 2021).

14. Dirección de Obras Hidráulicas. Manual de Drenaje Urbano; Ministerio de Obras Públicas, Ed.; Gobierno de Chile: Santiago, Chile, 2013.

15. Locatelli, L.; Russo, B.; Acero Oliete, A.; Carlos Sánchez Catalán, J.; Martínez-Gomariz, E.; Martínez, M. Modeling of E. coli distribution for hazard assessment of bathing waters affected by combined sewer overflows. Nat. Hazards Earth Syst. Sci. 2020, 20, 1219-1232. [CrossRef]

16. Federal Emergency Management Agency (FEMA). The Floodway: A Guide for Community Permit Officials; FEMA: Washington, DC, USA, 1979.

17. Martínez-Gomariz, E.; Locatelli, L.; Guerrero, M.; Russo, B.; Martínez, M. Socio-economic potential impacts due to urban pluvial floods in Badalona (Spain) in a context of climate change. Water 2019, 11, 2658. [CrossRef]

18. Clark County Regional Flood Control District (CCRFCD). Hydrological Criteria and Drainage Design Manual; Clark County Regional Flood Control District: Las Vegas, NV, USA, 1999.

19. Locatelli, L.; Guerrero, M.; Russo, B.; Martí nez-Gomariz, E.; Sunyer, D.; Martí nez, M. Socio-economic assessment of green infrastructure for climate change adaptation in the context of urban drainage planning. Sustainability 2020, 12, 3792. [CrossRef] 